\title{
PENCARIAN RUTE YANG HANDAL BERBASIS ENERGI MENGGUNAKAN ALGORITMA EA-SHORT PADA PROTOKOL ROUTING ZRP DI JARINGAN MANET
}

\author{
(Energy Based Route Search for Reliable Using EA-SHORT Algorithm on ZRP Routing \\ Protocol in Manet Network)
}

\author{
Mila Rosiana*, Andy Hidayat Jatmika, Ariyan Zubaidi \\ Program Studi Teknik Informatika, Fakultas Teknik, Universitas Mataram \\ JI. Majapahit 62, Mataram, Lombok NTB, INDONESIA \\ Email: rosianaa.mila@gmail.com, [andy, zubaidi13]@unram.ac.id
}

\begin{abstract}
Mobile Ad-Hoc Network (MANET) is a wireless network from a set of nodes that don't have a fixed router. Each node in this network acts as a router that is responsible for finding and handling routes between nodes. In this study, the concept of energy-aware routing using the EA-SHORT algorithm applied to the framework of the Zone Routing Protocol (ZRP). EA-SHORT tries to distribute network load to all existing nodes by utilizing variations in the amount of energy by selecting nodes that have enough energy that can participate in the route and avoiding nodes that have low energy. ZRP performance will be compared with EA-SHORT ZRP which has been modified with EA-SHORT measured from the specified parameter values. From the simulation, The results show, at node 50, throughput increased by 12,374\%. For 100 nodes, an increase of 44,597\%. On the average end to end delay, at 50 nodes the EA-SHORT ZRP value decreased by $20,063 \%$, node 100 EA-SHORT ZRP decreased by 8,375\%. PDR results on EA-SHORT ZRP with 50 nodes increased by $0.545 \%$, and for 100 EA-SHORT ZRP nodes increased by $21.301 \%$
\end{abstract}

Keywords: MANET, Energy Aware SHORT, ZRP, EA-SHORT ZRP

*Penulis Korespondensi

\section{Pendahuluan}

Mobile Ad-Hoc Network (MANET) adalah sebuah jaringan wireless dari kumpulan node yang tidak memiliki router tetap. Setiap node dalam jaringan ini memiliki fungsi sebagai router yang bertanggung jawab untuk mencari dan menangani rute antara node di dalam jaringan[1]. MANET memiliki komponen penting dalam proses penemuan rute yang disebut dengan proses routing[2]. Dalam proses transmisi data dari node sumber menuju node tujuan dibutuhkan komunikasi dengan mobile node terdekatnya. Hal tersebut bertujuan agar paket dapat diterima oleh node tujuan dengan efisien[3]. Protokol routing terdiri atas tiga macam yakni proaktif, reaktif dan hybrid. Protokol proaktif secara berkala melakukan pemeriksaan rute di jaringan, sehingga saat paket akan dikirim, rute sudah diketahui dan dapat langsung digunakan. Protokol reaktif sebaliknya melakukan pemeriksaan rute hanya ketika ada paket yang akan dikirim [4]. Protokol routing hybrid merupakan protokol yang menggabungkan konsep kerja reaktif dan proaktif[5].
Komponen penting lainnya pada MANET adalah energi, di mana energi pada setiap node yang beroperasi jumlahnya terbatas. Hal ini dikarenakan pada umumnya sumber energi node berasal dari baterai. Dengan jumlah energi yang terbatas, node juga mengoperasikan protokol routing dan berperan sebagai router, sehingga kinerja node menjadi meningkat dan membutuhkan energi yang lebih besar[6]. Pada routing, ketika rute optimal sudah ditemukan, maka rute akan disimpan dalam routing table, jika routing tidak menerapkan konsep energy aware maka setiap node yang berada dalam rute tersebut akan digunakan terus menerus dalam proses pengiriman paket, sedangkan node-node disekitarnya dibiarkan bebas. Hal tersebut mengakibatkan jumlah energi pada setiap node bervariasi[7].

Selain jumlah energi pada node yang bervariasi, dalam MANET, node yang bergerak secara bebas dan acak dapat menyebabkan topologi jaringan berubah dan tidak dapat diprediksi posisinya, dan hal ini dapat dimanfaatkan dalam proses perubahan rute, sehingga terputusnya rute (link failure) dalam jaringan yang disebabkan oleh node yang kehabisan energi dapat 
dicegah. Terputusnya rute akan menyebabkan menurunnya performa jaringan. Konsep energy aware salah satunya adalah EA-SHORT (Energy Aware-Self Healing and Optimizing Routing Techniques) yang mencoba mendistribusikan beban jaringan (load balancing) pada semua node yang ada dengan memanfaatkan variasi jumlah energi. Kehandalan suatu jaringan pada algortima EA-SHORT diukur meningkatnya performa jaringan dilihat dari parameter uji yang digunakan yakni meningkatanya nilai throughput dan packet delivery ratio serta menurunnya nilai average end to end delay.

Pada penelitian ini konsep routing dengan energy aware menggunakan algortima EA-SHORT untuk MANET akan diterapkan dalam kerangka protokol routing Zone Routing Protocol (ZRP) yang merupakan protokol hybrid. Protokol ini memiliki konsep membatasi area routing dari protokol proaktif dalam bentuk zona di setiap node. Sedangkan konsep protokol reaktif digunakan jika pengiriman paket berada diluar zona[8]. Pada ZRP, rute yang digunakan bisa saja tidak reliable, artinya setiap node yang berpartisipasi dalam rute bisa saja kehabisan energi pada saat sedang dilakukan pengiriman paket. Hal ini disebabkan karena protokol routing ZRP tidak melakukan proses penghitungan energi tiap node.

Kinerja protokol routing yang diukur adalah jumlah throughput, average end to end delay, dan packet delivery ratio (PDR), dengan menerapkan skenario yang berbeda yakni memvariasikan beberapa parameter simulasi. Simulasi protokol routing pada penelitian ini akan dilakukan dengan menggunakan tools network simulator 2 (NS2) versi 2.35, sedangkan untuk analisis terhadap parameter uji menggunakan AWK Script yang mempunyai kegunaan untuk mengurai file.tr yang terdapat pada NS2. Hasil simulasi dari kedua protokol akan analisa dan dibandingkan untuk mengetahui pengaruh penerapan EA-SHORT pada protokol ZRP.

\section{TINJAUAN PUStaKa}

Penelitian yang telah dilakukan sebelumnya yang berkaitan dengan penelitian yang akan dilakukan antara lain yakni penelitian tentang simulasi dan analisa pada protokol ZRP menggunakan simulator NS2 dengan melakukan perhitungan nilai Qos yakni throughput, delay dan PDR[5]. Jumlah node yang disimulasikan adalah, 10, 20, 50 dan 100. Dari hasil simulasi yang dilakukan, nilai throughput terendah terdapat pada 100 node dengan $34.5702 \mathrm{Kbps}$ dan tertinggi ditemukan di jaringan dengan jumlah 10 node, sebesar $727.081 \mathrm{Kbps}$. Sementara rata-rata delay terendah dalam jaringan dengan 10 node sama dengan 0,606597 s dan yang tertinggi di jaringan dengan 100 node, dengan rata-rata delay 2,00939 s. Untuk nilai hasil PDR dari simulasi yang dilakukan, nilai PDR terendah terdapat pada jaringan dengan 100 node, yaitu sebesar 71,6509\%, dan nilai PDR tertinggi terdapat pada jaringan dengan jumlah 10 node, yaitu sebesar $80,439 \%$. Dari hasil pengujian dapat diketahui jika semakin banyak jumlah node maka lalu lintas jaringan akan semakin padat dan menurunkan kualitas pelayanan. Persamaan penelitan ini dengan penelitian yang akan dilakukan, yakni menggunakan protokol routing ZRP. Perbedaannya terletak penambahan metode EA-SHORT yang akan dilakukan sedangkan penelitian sebelumnya tidak menggunakan metode.

Penelitian yang melakukan analisis perbandingan kinerja antara tiga protokol yakni AOMDV, DSDV dan ZRP di jaringan MANET [3]. Ketiga protokol tersebut disimulasikan dengan NS2 di lingkungan simulasi yang memiliki beberapa variasi luas area dan jumlah mobile node. Kinerja ketiga protokol tersebut diuji dan dianalisis kinerjanya berdasarkan beberapa parameter, yaitu throughput, average end to end delay, PDR dan normalized routing load. Jumlah node yang digunakan yakni 20,40, 80 dan 100 . Untuk luas area simulasi yang digunakan yakni 500 × 500, 800 × 800 dan 1000 × 1000 . Hasil pengujian untuk luas area $1000 \times 1000$, dimana ZRP memiliki nilai rata-rata PDR tertinggi sebesar $0.784 \%, 0.834 \%, 0.165 \%$, dan $0.143 \%$. ZRP mengalami penurunan nilai PDR yang sangat drastis ketika node berjumlah 80 dan 100 walapun sempat memiliki rasio tertinggi pada kepadatan node 40. ZRP memiliki nilai rata-rata throughput tertinggi, yaitu sebesar 79.985 bps, 83.420 bps, 16.573 kbps, dan 14.375 bps dan penurunan yang sangat drastis masih terjadi pada ZRP ketika node berjumlah 80 dan 100 . verage end to end delay juga mengalami peningkatan cukup jauh dari 0,278 s dan 0,310 s pada jumlah node 20 dan 40 menjadi 6,553 dan 11,556 s pada jumlah node 80 dan 100. Rata-rata untuk normalized routing load ZRP yakni 8.609 bytes, 23.528 bytes, 328.435 bytes, 955.22 bytes. Penelitian ini menujukkan bahwa performa ZRP mengalami penurunan seiring dengan bertambahnya jumlah node dan mengalami penurunan yang drastis antara jumlah node 24, 40 dengan 80, 100. Persamaan dengan penlitian ini dengan penelitian yang akan dilakukan yaitu protokol ZRP yang digunakan dan luas area 1000 m x 1000 m. Perbedaannya dengan penelitian yang akan dilakukan yakni pada penelitian ini tidak menerapkan metode apapun, sedangkan penelitian yang akan dilakukan akan diterapkan 
metode EA-SHORT untuk meningkatkan performa protokol ZRP.

Penelitian yang melakukan analisis Qos pada pada jaringan Ad Hoc dengan membandingkan protokol Ad hoc on Demand Distance Vector (AODV) dan ZRP dengan parameter uji yakni end to end delay, jitter, PDR dan troughput[9]. Hasil pengujian dengan luas area simulasi $1000 \mathrm{~m} \times 1000 \mathrm{~m}$ yakni ptotokol AODV dapat melakukan pegiriman paket lebih cepat. Kecepatan rata-rata $0.3134 \mathrm{~s}$ dari routing protokol ZRP dengan nilai 0.3891 detik, namun untuk jumlah paket yang terkirim routing protokol ZRP lebih baik dengan rata-rata troughput 963.34 bps dibandingkan routing protokol AODV. Persamaannya dengan penelitian yang akan dilakukan adalah menggunakan protokol ZRP dan cakupan luas area simulasi. Sedangkan perbedaannya yakni tidak ada penambahan metode energy aware pada penelitian sebelumnya.

Pada penelitian ini telah dilakukan analisis perbandingan kinerja antara protokol routing TORA dan TORA yang menerapkan algoritma SHORT[10]. Hasil simulasi menunjukkan bahwa throughput yang lebih tinggi meningkat hingga $3-50 \%$, end to end delay yang lebih rendah hingga $50 \%$, delay mengalami penurunan sebesar $50 \%$, penurunan packet loss bervariasi dari $12-57 \%$, perbaikan energi sekitar $43 \%$, dan life time jaringan yang lebih tinggi. TORA yang dimodifikasi mengungguli protokol routing TORA dalam hal throughput, packet loss, end-to-end delay, dan energi. Persamaan dari penelitian terkait dengan penelitian yang dilakukan yaitu menggunakan algoritma EA-SHORT. Sedangkan perbedaannya yaitu pada penelitian yang dilakukan menggunakan protokol routing ZRP namun penelitian sebelumnya menggunakan protokol routing TORA.

Penelitian yang melakukan analisis konsumsi energi pada protokol AODV, OLSR dan ZRP[11]. Penelitian ini melakukan analisis dengan parameter yakni routing power, throughput, konsumsi energi pada saat proses pengiriman, konsumsi energi pada saat penerimaan, dan end to end delay. Simulasi dilakukan selama 30 detik dengan luas area $1000 \mathrm{~m} x$ $1000 \mathrm{~m}$ dengan variasi jumlah node yakni 10, 20, 30, 40 dan 50. Hasil simulasi menunjukkan throughput tertinggi pada AODV dan OLSR dan terendah pada protokol ZRP. Pada nilai end to end delay, protokol terendah yakni OLSR. PDR tertinggi adalah AODV diikuti OLSR lalu ZRP. Total konsumsi energi saat pengiriman sangat rendah pada OLSR dibandingkan dengan dua protokol lainnya. Konsumsi energi terendah pada saat penerimaan yakni protokol ZRP. Routing power pada AODV adalah yang tertinggi namun mengalami penurunan jika dilihat dari rata-rata routing power AODV dalam setiap simulasi. Persamaan penelitian ini dengan penelitian yang akan dilakukan yakni menggunakan protokol ZRP, perbedaannya pada penelitian sebelumnya hanya melakukan analisa konsumsi energi sedangkan pada penelitian yang akan dilakukan, protokol ZRP akan diterapkan metode Algoritma EA-SHORT dalam pencarian rute.

Penelitian tentang energy aware dengan menggunakan algoritma EA-SHORT yang bertujuan untuk menyeimbangkan konsumsi energi semua node pada jaringan[7]. Penelitian ini melakukan simulasi menggunakan protokol AODV dengan menggunakan 120 node, luas area simulasi yakni $1200 \mathrm{~m}$ x 1200 m. Hasil uji coba dengan algoritma ini kemudian dibandingkan dengan AODV tanpa menggunakan EASHORT. Perbandingannya yakni jangka waktu atau lama hidup jaringan. Pada simulasi di detik 200 kapasitas kedua protokol masih relatif sama. Namun pada 1210 detik protokol AODV mulai mengalami interupsi karena partisi pada jaringan. Aliran data pada AODV terputus pada detik 1825, namun bertahan sampai akhir simulasi (2000 detik) menggunakan EASHORT. Persamaannya dengan penelitian yang akan dilakukan adalah menggunakan algoritma EA-SHORT, perbedaannya adalah penelitian selanjutnya akan menerapkan algoritma EA-SHORT pada kerangka protokol ZRP.

\section{Metode Penelitian}

\subsection{Diagram Alir Penelitian}

Gambar 1 merupakan diagram alir yang menggambarkan langkah-langkah yang akan dilakukan pada penelitian.

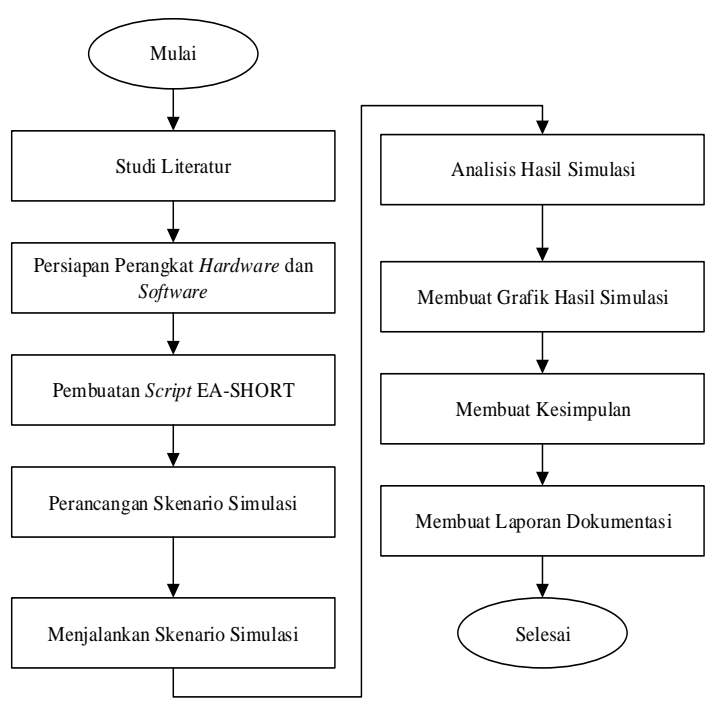

Gambar 1. Diagram alir penelitian 


\subsubsection{Studi literatur}

Pada tahap studi literatur, dilakukan pengkajian berbagai penelitian yang telah dilakukan sebelumnya terkait dengan penelitian yang akan dilakukan. Pada tahap ini, dilakukan pengkajian terhadap berbagai jurnal maupun paper mengenai performa protokol routing ZRP, teknik untuk memodifikasi routing protocol, teknik yang berkaitan dengan konsep energy aware untuk meningkatkan kehandalan jaringan berbasis energi mobile ad hoc network, dan beberapa penelitian lainnya yang mendukung penelitian yang akan dilakukan.

\subsubsection{Persiapan perangkat hardware dan sofware}

Uji coba dilakukan dengan menggunakan laptop Toshiba c640 dengan spesifikasi perangkat yang dapat dilihat pada Tabel 3.1

TABEL I. KOMPONEN HARDWARE DAN SOFTWARE

\begin{tabular}{|l|l|}
\hline Komponen & Spesifikasi \\
\hline CPU & $\begin{array}{l}\text { Intel(R) Core(TM) i3-2310M } \\
\text { CPU @ 2.10 GHz }\end{array}$ \\
\hline Sistem Operasi & Linux Ubuntu 16.04 LTS 64 bit \\
\hline Memori & $\begin{array}{l}2 \text { GB (Alokasi 1 GB untuk } \\
\text { instalasi Linux Ubuntu) }\end{array}$ \\
\hline Harddisk & $\begin{array}{l}297 \text { GB (Alokasi 10 GB untuk } \\
\text { penyimpanan data simulasi) }\end{array}$ \\
\hline
\end{tabular}

Adapun perangkat lunak yang digunakan pada penelitian ini adalah sebagai berikut:

a. Network Simulator 2 (NS2) versi 2.35 untuk melakukan simulasi jaringan MANET.

b. Virtual Box sebagai tempat instalasi linux.

NS2 akan diinstal pada sistem operasi linux yang akan diinstal secara virtual pada virtual box.

c. Microsoft Excel untuk membuat grafik hasil simulasi.

d. Linux Ubuntu 16.04 LTS 64 bit sebagai sistem operasi.

e. Microsoft Word, sebagai pembuatan dokumentasi

f. Microsoft Visio sebagai pembuatan diagram.

\subsubsection{Pembuatan skrip EA-SHORT}

Pembuatan skrip EA-SHORT ZRP dilakukan dengan cara memodifikasi kerangka protokol routing ZRP dengan menyisipkan Algoritma EA-SHORT. Penulisan kode dilakukan untuk pencarian rute yang handal berbasis energi dengan mekanisme perubahan rute. Jika rute baru ditemukan maka rute tersebut yang akan digunakan untuk melakukan pengiriman data.

\subsubsection{Perancangan skenario simulasi}

Pada bagian ini, peneliti melakukan perancangan skenario simulasi jaringan MANET untuk melakukan analisis pengaruh algoritma EA-SHORT pada protokol routing ZRP dengan kondisi yaitu protokol ZRP belum menggunakan EA-SHORT dan kondisi di mana ZRP sudah dimodifikasi menggunakan EA-SHORT.

Terdapat beberapa parameter uji yang digunakan untuk menganalisis hasil pengujian dari skenario simulasi yang dilakukan, yaitu:

a. Throughput

Throughput adalah kecepatan transfer data efektif yang merupakan jumlah total kedatangan paket data yang sukses diamati pada tujuan selama interval waktu tertentu dibagi dengan durasi interval waktu pengamatan.

Rumus:

Throughput $(\mathrm{Kbps})=\frac{\text { ukuran data yang dikirim }}{\text { total waktu pengiriman data }}$

\section{b. Average end to end delay}

Waktu jeda yang dibutuhkan dalam pengiriman paket dari pengirim ke penerima paket.

Rumus:

Average delay $(\mathrm{s})=\frac{\text { total delay }}{\text { total paket yang diterima }}$

c. Packet delivery ratio (PDR)

Perbandingan antara paket data yang terkirim dengan jumlah paket data yang diterima.

Rumus:

Packet Delivery Ratio (\%)

$$
=\frac{\text { paket data yang diterima }}{\text { paket data yang dikirim }} \times 100 \%
$$

\subsubsection{Menjalankan skenario simulasi}

Pada tahap ini skenario simulasi yang telah dibuat pada file.tcl dijalankan dengan perintah \#ns namafile.tcl.

\subsubsection{Analisis hasil simulasi}

Pada tahap ini dilakukan proses analisis terhadap hasil yang diperoleh dari proses pengujian skenario penelitian, dengan membandingkan hasil simulasi protokol routing ZRP dan protokol routing EA-SHORT ZRP, dengan percobaan pengiriman data dengan mobilitas node berdasarkan jumlah node, luas area, dan kecepatan node. Menggunakan script AWK, akan dilakukan analisis parameter berupa throughput, PDR, dan end to end delay. Hasil Analisa simulasi ditampilkan dalam bentuk grafik. Semakin besar nilai throughput dan PDR maka semakin banyak jumlah paket data yang dapat sampai ke tujuan dan semakin baik performa. Semakin rendah nilai end to end delay maka semakin 
cepat kemampuan protokol routing dalam menemukan jalur komunikasi data, sehingga semakin cepat dan semakin banyak data yang dapat sampai ke tujuan. Hasil pengujian yang dijalankan diharapkan dapat menunjukkan pengaruh penerapan algoritma EA-SHORT terhadap protokol routing ZRP pada lingkungan MANET.

\subsubsection{Membuat grafik hasil}

Pembuatan grafik Hasil dari simulasi yang telah dilakukan menggunakan Microsoft Excel. Grafik atau data-data tersebut kemudian dianalisis dan dapa digunakan untuk membandingkan performansi ZRP dengan EA-SHORT ZRP.

\subsubsection{Membuat kesimpulan}

Pada tahap ini akan dilakukan review terhadap hasil modifikasi protokol routing ZRP dan pengujian skenario, untuk mengetahui performa terbaik dari skenario yang telah diuji. Sehingga, dapat ditarik kesimpulan dari penelitian yang dilakukan serta saran sebagai masukan untuk penelitian selanjutnya.

\subsubsection{Membuat laporan dokumentasi}

Pada tahap ini akan dilakukan pembuatan laporan dokumentasi terhadap penelitian yang telah dilakukan. Dokumentasi laporan yang dibuat dapat membantu untuk penelitian selanjutnya yang berkaitan dengan penelitian yang dilakukan.

\subsection{Algoritma Pencarian Rute Menggunakan Protokol Routing ZRP}

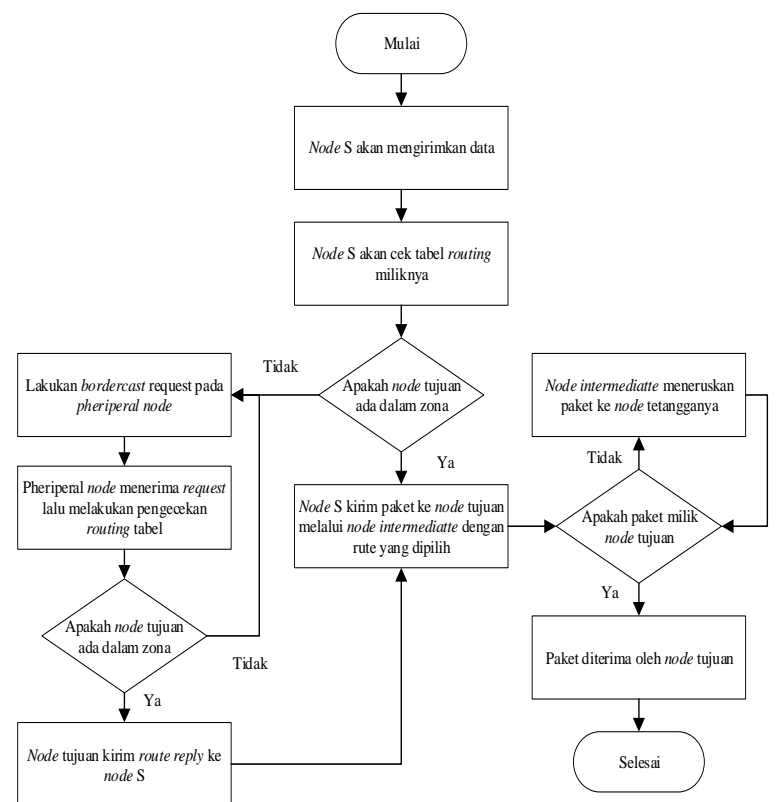

Gambar 2. Proses pencarian rute pada protokol routing ZRP
Dimisalkan jaringan pada Gambar 3, node $\mathrm{M}$ ingin mengirim paket menuju node $\mathrm{V}$. dengan radius zona adalah kurang atau sama dengan 2. Node akan menggunakan routing table yang disediakan oleh IARP untuk mengecek apakah node tujuan berada dalam zona atau tidak. Karena tujuan tidak ditemukan, maka dilakukan route request menggunakan IERP. Pesan request diteruskan ke peripheral node yakni $A, O, P, S$. kemudian setiap node ini juga akan mengecek tujuan paket pada tabel routing-nya.

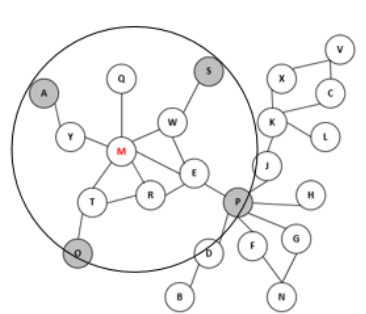

(a)

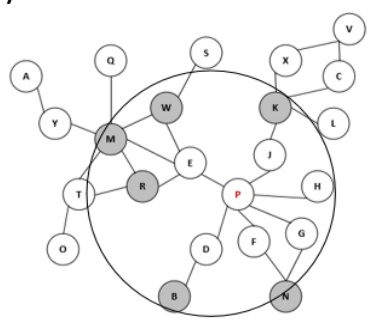

(b)
Gambar 3. (a) Routing zone pada node M; (b) Routing zone pada node $\mathrm{P}$

Node $\mathrm{P}$ tidak menemukan tujuan paket pada routing table-nya, lalu pesan akan diteruskan ke pheriperal node yakni node yang ditandai dengan warna abu-abu, karena adanya mekanisme query control, maka request tidak diteruskan ke node $\mathrm{W}, \mathrm{M}, \mathrm{R}$.

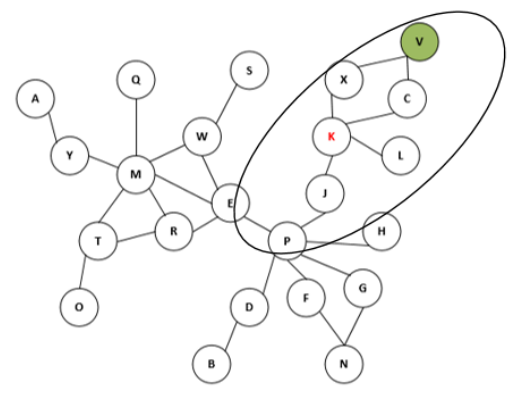

Gambar 4. Routing zone pada node $\mathrm{K}$

Ketika route request diterima oleh pheriperal node dari $\mathrm{P}$, dan diterima oleh node $\mathrm{K}$, dimana node $\mathrm{K}$ menemukan tujuan dari route request yang ditunjukkan dengan warna hijau pada Gambar 3.5 yakni node $\mathrm{V}$ yang berada dalam zona node $\mathrm{K}$. node $\mathrm{K}$ akan menambahkan jalur menuju node pada jalur di route request. Pesan berupa route reply yang dengan jalur dari node tujuan (node $\mathrm{V}$ ) ke node pengirim (node $\mathrm{M})$ berupa reversed path dan dikirim ke node $\mathrm{M}$. jika multipath ke node tujuan tersedia, maka node sumber akan menerima beberapa route reply.

\subsection{Algoritma EA-SHORT ZRP}

Pencarian rute dengan menggunakan algoritma EA-SHORT dapat ditunjukkan pada Gambar 5 dan Gambar 6. 


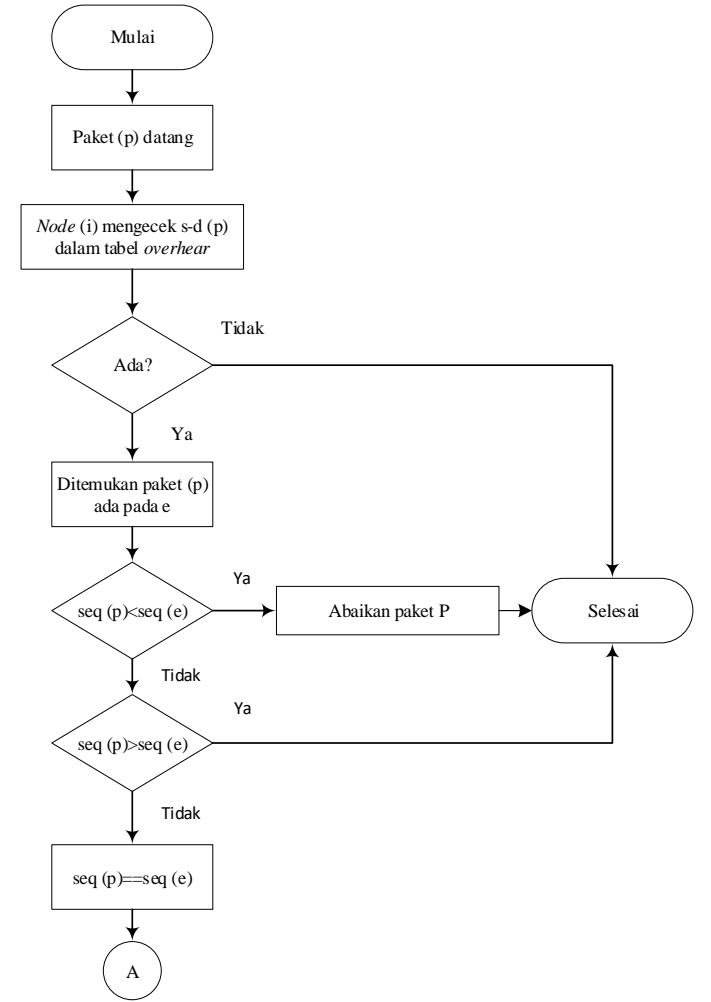

Gambar 5. Flowchart pencarian rute pada EA-SHORT

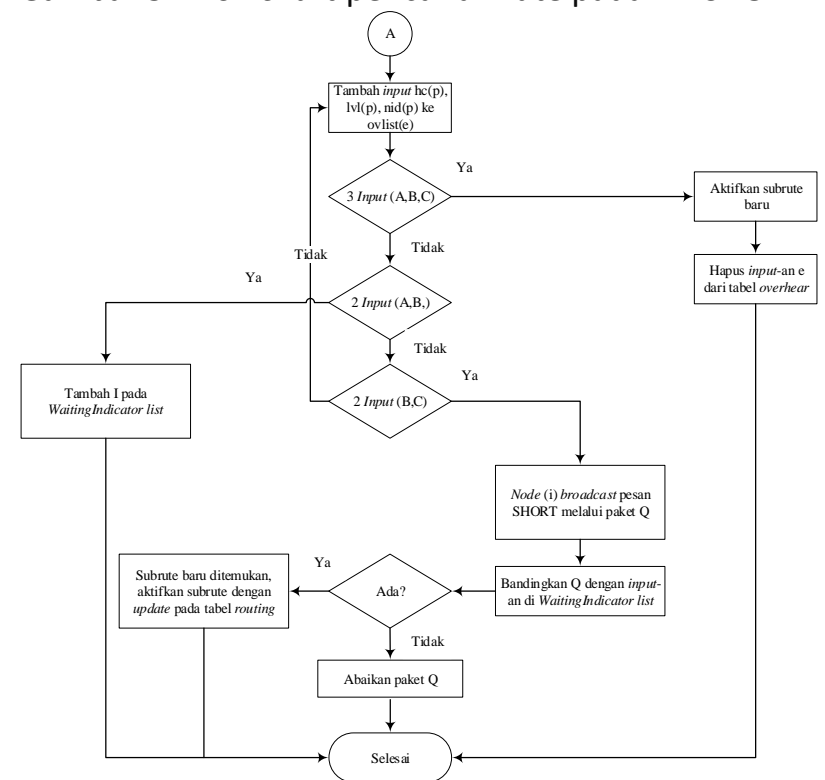

Gambar 6. Flowchart pencarian rute pada EA-SHORT (Lanjutan Gambar 5)

Mekanisme EA-SHORT dalam Gambar 5 dan Gambar 6 dapat dijelaskan sebagai berikut:

Jika suatu node (i) mengetahui kedatangan paket $\mathrm{P}$, Maka;

a. Node akan melakukan pengecekan rute untuk paket $\mathrm{P}$ pada tabel overhear. Tabel overhear merupakan tabel yang digunakan oleh node untuk menyimpan rute suatu paket. b. Jika tidak ada rute yang cocok. Tambahkan input variabel $e^{\prime}$, dimana rute $\left(e^{\prime}\right)$ sama dengan rute $(p)$, sequence number $\left(\mathrm{e}^{\prime}\right)$ sama dengan sequence number $(p)$ lalu jadikan rute $\left(e^{\prime}\right)$ sebagai list rute pertama pada tabel overhear dengan isi ( $\left.e^{\prime}\right)$ berupa hop count $(p)$, level energi $(p)$, dan nomer id $(p)$. Proses selesai.

c. Misalkan rute (p) ditemukan pada input-an e, dengan kondisi sequence number ( $p$ ) kurang dari sequence number (e), maka $\mathrm{p}$ akan diabaikan, dan proses selesai.

d. Jika sequence number ( $p$ ) lebih besar dari sequence number pada (e), maka perbaharui e dengan ketentuan yakni sequence number (e) sama dengan sequence number $(p)$, list rute pada tabel overhear (e) direset sehingga memiliki satu input-an rute dengan isi hop count ( $p)$, level energi ( $p)$. nomer id (p) dan proses selesai.

e. Jika sequence number (p) sama dengan sequence number (e), maka:

1. Tambahkan input-an <hc (p), Ivl (p), nid (p)> ke ov-list (e).

2. Jika daftar overhear pada (e) memiliki tiga input-an yakni $A, B, C$ yang memenuhi kondisi berikut, maka subpath ditemukan.

- Hop count pada (C) sama dengan hop count (B)+1 dan sama dengan hop count (A) +2

- Level energi pada (node i) lebih besar atau sama dengan jumlah maksimal energi pada ((A) dan level energi pada (C));

- level energi pada (node i) - level energi(B) $\geq 2$, maka akan diaktifkan sub-rute baru, dan hapus input-an (e) dari tabel overhear.

3. Jika daftar overhear pada (e) memiliki dua input-an, yakni $A$ dan $B$, dengan kondisi hop count (B) sama dengan hop count (A)+1 dan level energi pada pada node (i) $\geq$ maksimal level energi (A) dan dan level energi (B) +2 , tambahkan indikator I pada daftar tunggu indikator (WaitingIndicator List), dengan kandidat (I) sama dengan B. sequence number (I) disamakan dengan (e). rute (I) sama dengan rute (e), maka proses selesai.

4. Jika daftar overhear (e) memiliki dua input-an B dan C, dengan kondisi hop count (C) sama dengan hop count (B)+1 dan level energi pada node (i) $\leq$ dari maksimal level energi pada $(\mathrm{B})+2$ dan level energi (C), maka node I akan menyebarkan pesan SHORT untuk 
menginformasikan paket $Q$ dengan ketentuan kandidat $(Q)$ sama dengan $B$, sequence number pada ( $Q$ ) sama dengan sequence number pada (e), dan rute ( $Q$ ) sama dengan rute pada (e).

Ketika node i menerima paket informasi pesan SHORT Q, maka:

- Bandingkan bidang $\mathrm{Q}$ dengan input-an yang valid dalam WaitingIndicator list.

- Jika tidak ada yang cocok, maka abaikan paket Q;

Jika kondisi tidak terpenuhi, maka subrute yang lebih baik ditemukan. Aktifkan subrute ini dengan memperbaharui tabel routing. Proses selesai.

Contoh rute pada MANET yang dilakukan penerapan EA-SHORT

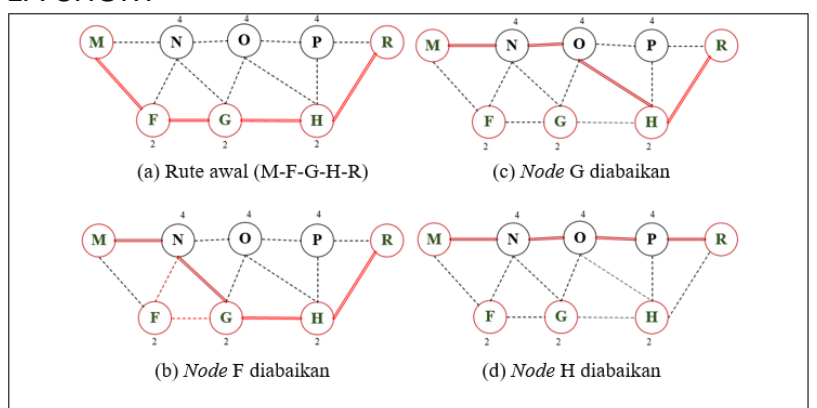

Gambar 7. Contoh proses perutean ulang dengan menggunakan algoritma EA-SHORT

Pada Gambar 7, menunjukkan contoh peroses perutean ulang dengan menggunakan algortima EASHORT, dimana rute awalnya yakni M-F-G-H-R (a). Terdapat node tetangga yakni $\mathrm{N}, \mathrm{O}, \mathrm{P}$. Node $\mathrm{N}$ mengidentifikasi node $\mathrm{F}$ akan kehabisan energi dan kurang dari batas jumlah energi yang ditentukan dalam perutean, setelah dibandingkan dengan jumlah energi $\mathrm{N}$, ternyata jumlah energi $\mathrm{N}$ lebih besar dari node $\mathrm{F}$, sehingga node $\mathrm{F}$ diabaikan, rute berubah menjadi $\mathrm{M}-\mathrm{N}$ G-H-R (b). Node G diabaikan (c) kerena node O mengidentifikasi jumlah energi node $\mathrm{G}$ yang hampir habis dan jumlah energi node $\mathrm{O}$ lebih besar, rute berubah menjadi M-N-O-H-R. Hal yang sama dilakukan pada node $\mathrm{H}, \mathrm{P}$ mengidentifikasi jumlah energi node $\mathrm{H}$, perutean ulang dilakukan karena energi $P$ lebih besar dan jumlah energi $\mathrm{H}$ kurang dari batas jumlah energi yang ditetapkan (nilai threshold). Rute akhir setelah proses perutean ulang dengan algoritma EA-SHORT adalah M-N-O-P-R (d).

\subsection{Parameter Skenario Simulasi}

Parameter skenario simulasi digunakan sebagai suatu pengukuran tentang seberapa baik jaringan dan merupakan suatu usaha untuk mendefinisikan karakteristik dan sifat dari suatu layanan. Dengan parameter performansi, suatu jaringan dapat memenuhi layanan yang berbeda menggunakan infrastruktur yang sama. Pada bagian ini merupakan skenario simulasi yang akan diimplementasikan menggunakan NS-2 versi 2.35. Link layer yang digunakan adalah berdasarkan pada standar IEEE 802.11. Fungsi koordinasi terdistribusi IEEE 802.11 untuk nirkabel LAN digunakan sebagai lapisan MAC. Jumlah node yang ada pada area sebanyak 50 dan 100 node [3]. Simulasi dilakukan pada area persegi (network area) dengan ukuran $1000 \mathrm{~m} \times 1000 \mathrm{~m}$ [3]. Waktu simulasi yang dilakukan selama $2000 \mathrm{~s}$ [7]. Digunakan variasi kecepatan node untuk melihat perbandingan kinerja kedua protokol, yakni sebesar 1 $\mathrm{m} / \mathrm{s}, 5 \mathrm{~m} / \mathrm{s}$, dan $10 \mathrm{~m} / \mathrm{s}$ serta menggunakan variasi pause time selama $45 \mathrm{~s}, 90 \mathrm{~s}$, dan $180 \mathrm{~s}$ untuk mengetahui perbandingan kinerja kedua protokol. Jenis mobilitas yang digunakan pada simulasi adalah Random Waypoint. Setiap node secara independen memilih destination yang hendak dituju secara acak di dalam batasan jaringan. Parameter skenario dapat dilihat pada Tabel 2.

TABEL II PARAMETER SKENARIO SIMULASI

\begin{tabular}{|c|c|}
\hline \multicolumn{2}{|c|}{ Parameter Skenario } \\
\hline Tipe Parameter & Nilai Parameter \\
\hline MAC Layer & IEEE 802.11 \\
\hline Jumlah node & 50,100 \\
\hline Network area & $1000 \mathrm{~m} \times 1000 \mathrm{~m}$ \\
\hline Waktu simulasi & $200 \mathrm{~s}$ \\
\hline Kecepatan node & $1 \mathrm{~m} / \mathrm{s}, 5 \mathrm{~m} / \mathrm{s}, 10 \mathrm{~m} / \mathrm{s}$ \\
\hline Pause time & $45 \mathrm{~s}, 90 \mathrm{~s}, 180 \mathrm{~s}$ \\
\hline Pergerakan node & Random Waypoint \\
\hline Propagation & TwoRayGround \\
\hline Antena & Omni antenna \\
\hline Pola traffic & CBR \\
\hline Channel & Wireless \\
\hline
\end{tabular}

\section{Hasil dan PEMBahasan}

\subsection{Hasil Pengujian Terhadap Throughput}

Throughput merupakan jumlah rata-rata pengiriman paket data yang diterima setiap detiknya. Pada situasi ZRP standar, energi pada setiap node akan berkurang selama simulasi berjalan dan link akan terputus ketika energi pada node habis. Dalam kondisi ini, akan terjadi route error dan paket akan dikirim kembali menuju node sumber, dan node sumber akan menghapus link tersebut dalam topologi tabel-nya dan node akan melakukan update tabel dan menentukan kembali rute terdekat untuk mencapai node tujuan. 
Setelah dilakukan penerapan algoritma pada kerangka protokol ZRP, dengan memperhatikan nilai energi pada setiap node agar tidak terjadi link failure dalam prosesnya. Hasil throughput sebelum dan sesudah penerapan algoritma dapat dilihat perbandingan hasilnya dalam bentuk grafik pada Gambar 8 .

Berdasarkan grafik throughput pada Gambar 8 dan Gambar 9, menunjukkan bahwa kondisi protokol sesudah diterapkan algoritma EA-SHORT memiliki kualitas lebih baik daripada protokol ZRP standar. Berdasarkan kecepatan node, maka semakin besar kecepatan node maka nilai throughput semakin rendah. Kecepatan node menyebabkan posisi node dalam topologi jaringan bergerak dan data merusak rute yang telah ada. Sehingga semakin besar kecepatan node, maka kemungkinan rute menjadi terputus semakin tinggi sehingga dapat menurunkan kualitas throughput.

Dari hasil throughput, jika dilihat berdasarkan pause time, nilai throughput mengalami peningkatan seiring dengan bertambahnya jumlah pause time, nilai pause time yang lebih tinggi artinya node berada dalam posisi diam yang lebih lama (stabil) sehingga menurunkan kemungkinan kerusakan rute akibat pergerakan node. Hal inilah yang menyebabkan nilai throughput lebih baik.

Nilai throughput pada 50 node lebih tinggi daripada 100 node. Jumlah node yang semakin bertambah membuat kecepatan throughput berkurang. Hal ini disebabkan karena kepadatan trafik yang lebih tinggi dan lebih banyak zona yang terbentuk oleh ZRP. Karena setiap node memiliki informasi node tetangga pada zona lokalnya, maka semakin banyak jumlah node yang tersedia menyebabkan semakin banyak jumlah trafik sehingga menyebabkan kongesti pada node perantara, kongesti adalah suatu kondisi dimana node perantara menanggung beban yang melebihi kapasitas jaringan. Hal ini menyebabkan beberapa paket akan di drop, sehingga mengakibatkan throughput koneksi utama menjadi turun.

EA-SHORT ZRP membuktikan dapat menghasilkan nilai throughput yang lebih baik dibandingkan ZRP standar baik pada skenario dengan 50 node ataupun 100 node. Hal ini disebabkan algoritma EA-SHORT mengantisipasi terjadinya kerusakan rute akibat energi yang terdapat pada node habis dengan mengalihkannya pada node terdekatnya (load balancing). Antisipasi yang dilakukan sebelum rute terputus menyebabkan waktu yang dibutuhkan untuk mengirim paket lebih rendah. Nilai throughput meningkat pada EA-SHORT ZRP dikarenakan rata-rata end to end delay mengalami penurunan sehingga

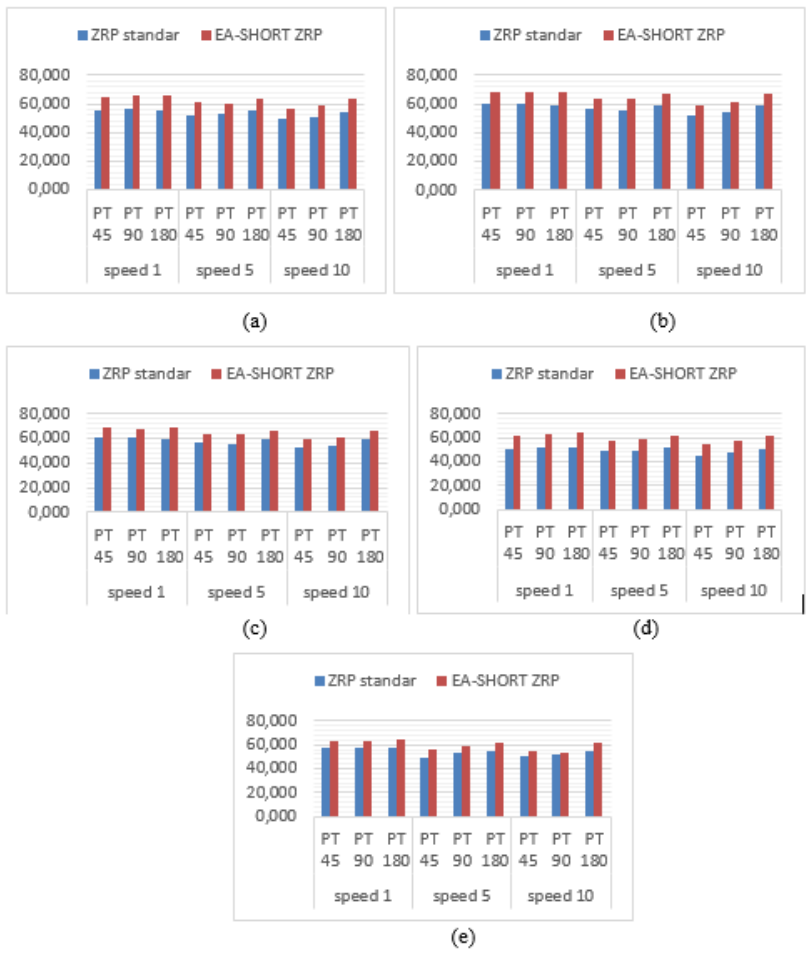

Gambar 8. Grafik perbandingan hasil uji coba 50 node terhadap nilai throughput pada (a) uji coba ke 1 (b) uji coba ke 2, (c) uji coba ke 3, (d) uji coba ke 4 (e) uji coba ke 5

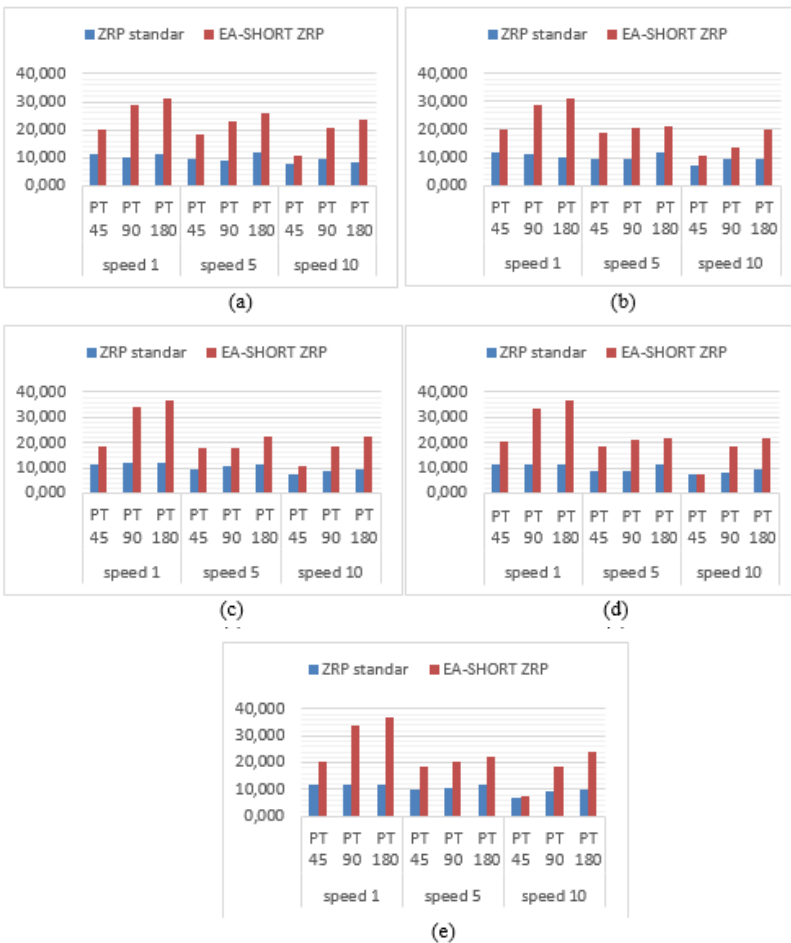

Gambar 9. Grafik perbandingan hasil uji coba 100 node terhadap nilai throughput pada (a) uji coba ke 1, (b) uji coba ke 2, (c) uji coba ke 3, (d) uji coba ke 4 (e) uji coba ke 5 
jumlah paket yang dapat sampai ketujuan meningkat. EA-SHORT ZRP meningkatkan nilai throughput dengan memastikan paket tersebut melewati rute yang handal dengan kualitas energi yang cukup sehingga tidak terjadi link failure.

\subsection{Hasil Pengujian Terhadap Average End-to-end Delay}

Average End-to-end delay adalah rata-rata dari jumlah waktu yang digunakan oleh sebuah paket ketika dikirim oleh sebuah node dan diterima di node tujuan. Faktor yang sangat mempengaruhi average end-to-end delay adalah waktu untuk routing protokol tersebut dalam menemukan rute, hal ini dikarenakan sebelum mengirim pesan, node sumber terlebih dahulu harus mengetahui rute yang menghubungkan ke node tujuan. Selain itu dapat dipengaruhi oleh proses delay pengiriman paket dari satu node ke node lainnya karena membutuhkan waktu untuk menganalisis harus dibawakan paket tersebut. Dalam proses pengiriman paket di luar zona, protokol ZRP akan melakukan bordercast paket RREQ pada peheriperal node dan menyebabkan delay meningkat. Jika dalam tabel routing pheriperal node tujuan tidak ditemukan, maka akan dilakukan bordercast lagi sampai node tujuan paket ditemukan.

Berikut merupakan hasil dan grafik kualitas average end-to-end delay berdasarkan jumlah node yaitu 50 dan 100, variasi kecepatan node dan pause time, seperti pada Gambar 10.

Berdasarkan grafik rata-rata average end-to-end delay pada Gambar 10 dan Gambar 11, bahwa average end to end delay setiap skenario pada 50 node dan 100 node mengalami perubahan pada setiap parameter simulasi. Perubahan kecepatan pada node menyebabkan perubahan hasil pada nilai average end to end delay. Pada node 100, nilai rata-rata average end to end delay lebih tinggi dibandingkan dengan average end to end delay pada node 50, dikarenakan jaringan yang lebih padat dan lebih banyak transmisi data yang dilakukan dan pada 100 node, zona yang terbentuk menjadi lebih banyak dibandingkan node 50 , sehingga node sumber melalui IERP akan lebih sering melakukan bordercast terlebih dahulu saat akan mengirim paket.

Kecepatan node juga berpengaruh pada hasil average end to end delay. Semakin tinggi kecepatan node, maka nilai average end to end delay semakin tinggi. Hal ini dikarenakan perubahan pada posisi node yang lebih cepat dan posisi node menjadi tidak stabil, dan mengakibatkan kerusakan pada rute sehingga IARP lebih sering melakukan pemeliharaan rute. Semakin sering pemeliharaan rute dilakukan, maka

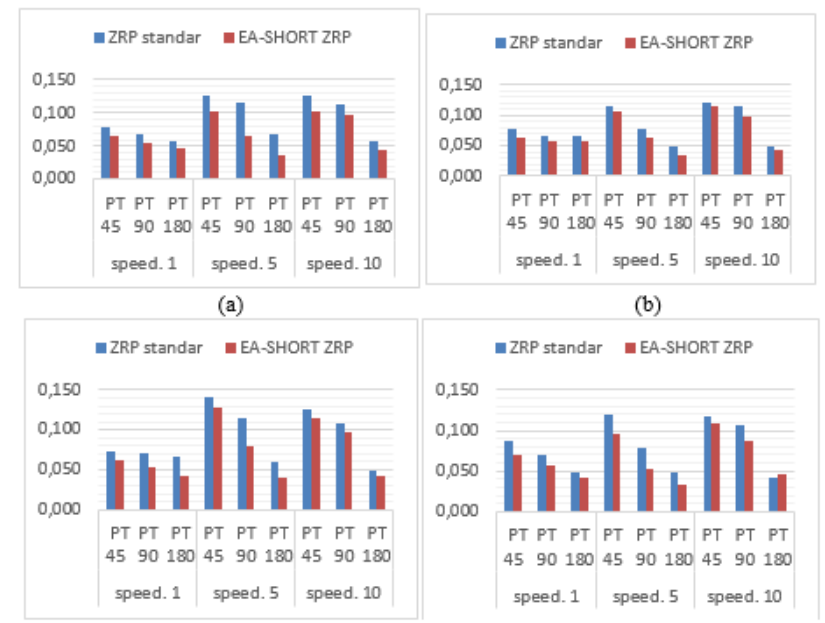

(c)

(d)

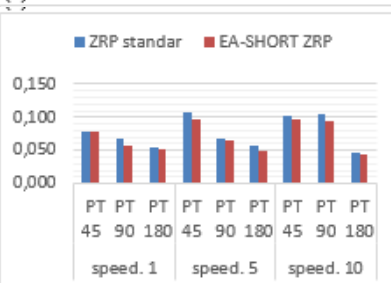

(e)

Gambar 10. Grafik perbandingan hasil uji coba 50 node terhadap nilai average end to end delay pada (a) uji coba ke 1, (b) uji coba ke 2, (c) uji coba ke 3, (d) uji coba ke 4, (e) uji coba ke 5

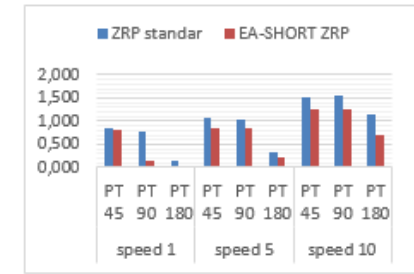

(a)

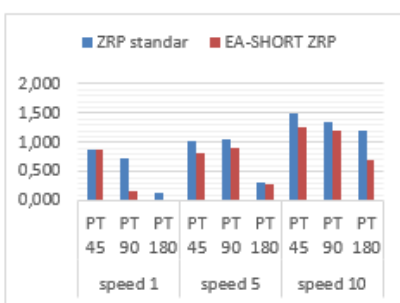

(c)

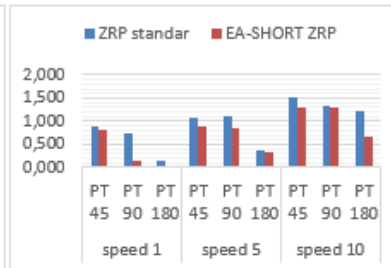

(b)

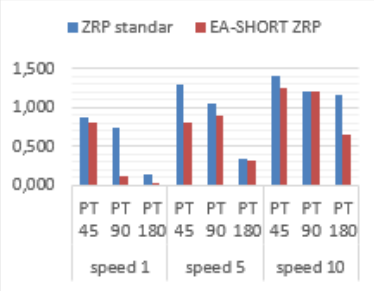

(d)

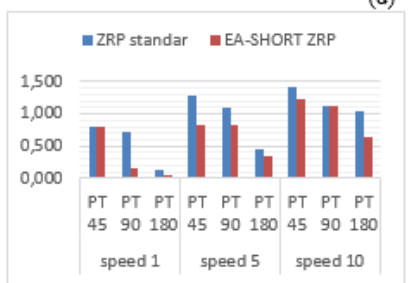

(e)

Gambar 11 Grafik perbandingan hasil uji coba 100 node terhadap nilai average end to end delay pada (a) uji coba ke 1, (b) uji coba ke 2, (c) uji coba ke 3, (d) uji coba ke 4, (e) uji coba ke 5 
semakin tinggi nilai average end to end delay, hal ini menyebabkan nilai buffer pada paket data jaringan semakin tinggi. Perubahan pause time juga membuat perubahan pada nilai average end to end delay. Semakin tinggi nilai pause time, maka nilai average end to end delay semakin rendah, karena pause time yang lebih tinggi menyebabkan posisi node lebih stabil dan pengiriman paket dapat berjalan dengan baik. Selain kerusakan rute akibat pergerakan node, padatnya transmisi pada jaringan juga berakibat pada menurunnya jumlah energi yang lebih cepat, sehingga kemungkinan kerusakan rute akibat node kehabisan energi juga menjadi lebih tinggi.

Hasil penerapan algoritma EA-SHORT pada protokol ZRP, menujukkan algoritma ini dapat menurunkan nilai average end to end delay. Dikarenakan algoritma EA-SHORT memastikan paket memiliki rute yang stabil dengan jumlah energi yang cukup selama proses transmisi. Sehingga jika rute mengalami perubahan akibat pergerakan node, algoritma EA-SHORT akan mengusahakan perubahan rute yang lebih baik kualitas energinya dibandingkan dengan ZRP standar. Dari rata-rata hasil pada setiap uji coba, didapatkan kualitas average end to end delay mengalami peningkatan seiring dengan bertambahnya jumlah speed yang digunakan. Hal ini dikarenakan topologi jaringan berubah lebih cepat dan lebih jauh pada area yang luas sehingga menyebabkan proses transmisi data menjadi lebih lama karena hop yang lebih panjang, dan kemungkinan untuk terjadi kerusakan rute lebih tinggi jika pergerakan node lebih cepat sehingga menemukan rute yang baru akan meningkatkan nilai delay. Pada setiap kondisi jumlah node memiliki kenaikan kualitas yang beragam dikarenakan kondisi simulasi jaringan yang bergerak secara random (kondisi random waypoint).

\subsection{Hasil Pengujian Terhadap PDR}

Skenario uji coba ketiga adalah mencari nilai perbandingan antara paket data yang terkirim (paket data yang berhasil diterima oleh node tujuan) dengan jumlah paket data yang dikirimkan oleh node sumber (paket data yang di-generate node sumber). Hasil dari peregrakan node terhadap PDR dapat dilihat pada grafik yang terdapat pada Gambar 12 dan 13.

Hasil nilai PDR yang dihasilkan pada kelima percobaan Gambar 12 dan Gambar 13 memperlihatkan nilai PDR pada EA-SHORT ZRP lebih tinggi daripada ZRP standar. Kecepatan pada node yang berubah menyebabkan nilai PDR juga berubah. Semakin tinggi kecepatan node, semakin rendah nilai PDR yang dihasilkan, perubahan rute karena kondisi node yang tidak stabil menyebabkan lebih banyak rute yang terputus dan terjadi paket drop.

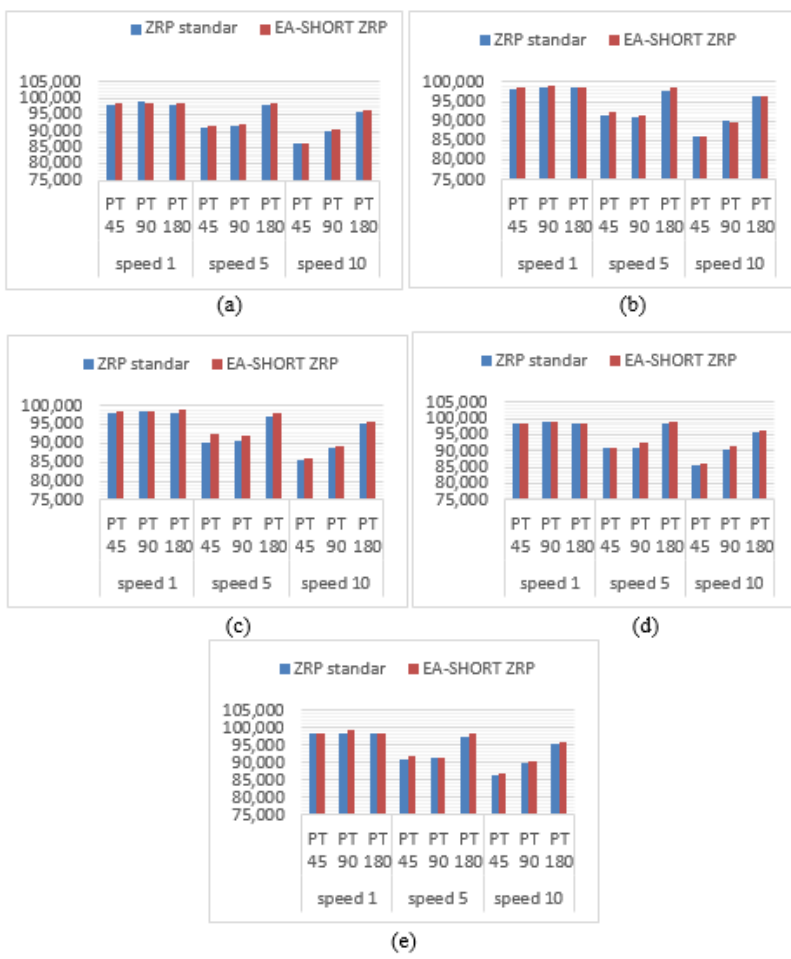

Gambar 12. Grafik perbandingan hasil uji coba 50 node terhadap nilai PDR pada (a) uji coba ke 1, (b) uji coba ke 2, (c) uji coba ke 3, (d) uji coba ke 4 (e) uji coba ke 5

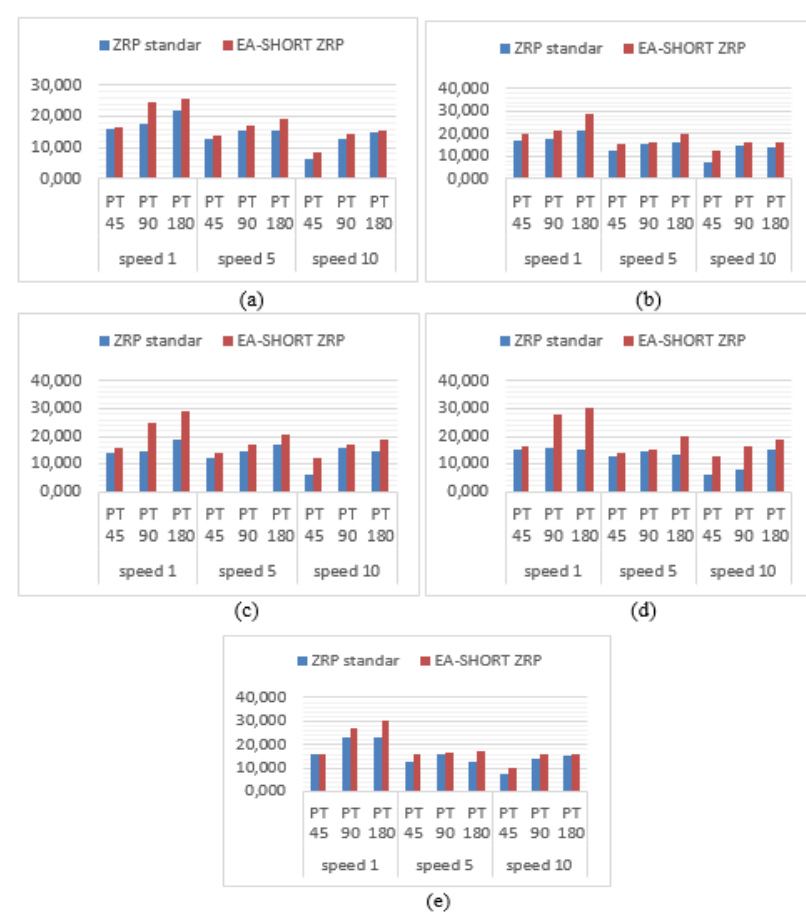

Gambar 13. Grafik perbandingan hasil uji coba 100 node terhadap nilai PDR pada (a) uji coba ke 1, (b) uji coba ke 2, (c) uji coba ke 3, (d) uji coba ke 4 (e) uji coba ke 5 
Nilai PDR dengan 50 node, baik untuk ZRP standar ataupun EA-SHORT ZRP tidak jauh berbeda. Node 50 pada area $1000 \mathrm{~m} \times 1000 \mathrm{~m}$ masih menghasilkan nilai rata-rata PDR yang cukup tinggi. Namun, EA-SHORT ZRP menghasilkan nilai rata-rata yang lebih tinggi pada setiap percobaan dibandingkan dengan ZRP standar. Hal ini karena EA-SHORT ZRP berusaha memastikan paket sampai ketujuannya dengan mengalihkan rute (load balancing) menuju tetangga terdekatnya sebelum rute terputus akibat habisnya energi pada node selama transmisi. Hal ini dikarenakan semakin padat lingkungan simulasi, yang menyebabkan kemungkinan terjadinya putus link antar node semakin rendah, sehingga jumlah paket yang di-drop juga akan semakin berkurang.

Nilai PDR dengan 100 node, lebih rendah pada ZRP standar dibandingkan EA-SHORT ZRP dan besarnya berbeda cukup jauh dibandingkan nilai PDR pada 50 node yang menghasilkan nilai rata-rata PDR yang cukup tinggi. Pada 100 node, nilai PDR mengalami penururan karena beberapa faktor seperti node yang lebih banyak dengan luas area yang besar sehingga menyebabkan jaringan menjadi lebih padat dan menurunkan kualitas pelayanan jaringan. Namun, EA-SHORT ZRP menghasilkan nilai rata-rata yang lebih tinggi pada setiap percobaan dibandingkasn dengan ZRP standar. Hal ini karena pada area yang luas, EA-SHORT ZRP berusaha memastikan suatu paket agar paket dapat sampai ke tujuan dengan mengalihkan rute paket ke tetangga terdekatnya (load balancing).

\section{KeSIMPULAN DAN SARAN}

\subsection{Kesimpulan}

Dari hasil simulasi dan penjelasan yang telah dipaparkan sebelumnya, dapat ditarik beberapa kesimpulan, yaitu:

a. Penerapan algoritma EA-SHORT pada jaringan MANET menggunakan protokol ZRP menunjukkan bahwa protokol routing EA-SHORT ZRP lebih baik dari pada protokol routing ZRP standar, baik dari segi throughput, average end-to-end delay dan PDR.

b. Hasil simulasi yang dilakukan, performa protokol routing ZRP dengan menggunakan algoritma EASHORT meningkatkan kualitas pada throughput. Hasil 50 node terhadap throughput pada EASHORT ZRP mengalami rata-rata peningkatan, $12,374 \%$ dari ZRP standar. Untuk 100 node, peningkatan EA-SHORT ZRP sebesar 44,597\% dibandingkan ZRP standar. Hasil uji coba terhadap nilai average end to end delay, pada 50 node nilai EA-SHORT ZRP turun sebesar $20,063 \%$, pada node
100 EA-SHORT ZRP mengalami penurunan sebesar 8,375 \% dari ZRP standar. Hasil PDR pada EASHORT ZRP dengan 50 node mengalami peningkatan sebesar 0,545 \% dari ZRP standar, dan untuk 100 node EA-SHORT ZRP mengalami peningkatan sebesar $21,301 \%$.

\subsection{Saran}

Dari penelitian yang telah dilakukan terhadap penerapan algoritma EA-SHORT pada protokol routing ZRP, dari kesimpulan yang telah dipaparkan, maka peneliti dapat memberikan saran sebagai berikut:

a. Melakukan penelitian menggunakan protokol routing yang sama dengan parameter simulasi yang berbeda dengan menggunakan jumlah node lebih banyak dan pause time lebih variasi serta model pergerakan node yang berbeda.

b. Melakukan penelitian dengan membandingkan performa jaringan MANET menggunakan algoritma EA-SHORT dengan algoritma atau metode energy aware yang lain.

\section{DAFTAR PUSTAKA}

[1] K. Raheja and S. K. Maakar, "A Survey on Different Hybrid Routing Protocols of MANET," Int. J. Comput. Sci. Inf. Technol., vol. 5, no. 4, pp. 5512-5516, 2014.

[2] A. H. Jatmika, S. Djanali, and M. Husni, "Optimasi Routing pada Jaringan MANET," Pros. Semin. Nas. Manaj. Teknol. XIII, pp. 1-7, 2011.

[3] E. R. Widasari and A. Bhawiyuga, "Analisis Perbandingan Kinerja Protokol AOMDV , DSDV , Dan ZRP Sebagai Protokol Routing Pada Mobile Ad-Hoc Network ( MANET )," J. Pengemb. Teknol. Inf. dan Ilmu Komput., vol. 2, no. 10, pp. 3671-3680, 2018.

[4] E. S. Gsr, N. Gayathri, A. Rai, and J. K. R, "Energy Aware Zone Routing Protocol for MANET," Asian J. Pharm. Clin. Res., vol. 10, no. 1, pp. 437-440, 2017.

[5] S. A. Sasongko and A. A. Zahra, "Analisis Performansi dan Simuasi Protokol ZRP ( Zone Routing Protocol) pada MANET ( Mobile Ad Hoc Network) dengan Menggunakan NS-2," pp. 1-8, 2012.

[6] I. N. R. Hendrawan, "Simulasi Penggunaan Energi pada Protokol Routing OLSR dengan Simulator ns-3," SNAPTI, pp. 3-6, 2016.

[7] C. Gui and P. Mohapatra, "SHORT : Self-Healing and Optimizing Routing Techniques for Mobile Ad Hoc Networks," Proc. 4th ACM Int. Symp. Mob. ad hoc Netw. Comput., pp. 279-290, 2003.

[8] Z. J. Haas and M. R. Pearlman, "On the performance of a routing protocol for the Reconfigurable Wireless Networks," IEEE Veh. Technol. Conf., vol. 1, no. C, 
pp. 102-106, 1998.

[9] B. S. Kusuma, D. Risqiwati, and D. R. Akbi, "Analisis Perbandingan Performansi Protokol Ad Hoc OnDemand Distance Vector dan Zone Routing Protocol Pada Mobile Ad Hoc Network," Kinetik, vol. 2, no. 3, pp. 165-175, 2017.

[10] A. H. Networks, R. Asokan, A. M. Natarajan, and C. Venkatesh, "Quality-of-Service Routing Using Path and Power Aware Techniques in Mobile Ad Hoc Networks," J. Comput. Syst. Networks, Commun., no. 2, p. 7, 2014.

[11] M. Otmani and A. Ezzati, "Performance Evaluation of Energy Consumption of Ad hoc Routing Protocols Abstract:," Int. J. Comput. Eng. Reasearch, vol. 04, no. 4, pp. 30-37, 2014. 